\title{
WINTER SURVIVAL OF NORTHERN PINTAILS IN THE MIDDLE RIO GRANDE VALLEY, NEW MEXICO
}

\author{
Colin K. Lee ${ }^{1,2}$, John P. Taylor ${ }^{3,4}$, David A. Haukos ${ }^{5}$, Mark C. Andersen ${ }^{1}$
}

\begin{abstract}
In response to continued low population numbers of Northern Pintail (Anas acuta) in North America and to increase knowledge of the geographic variation in pintail survival rates, we estimated 126-day (27 October-2 March) survival for male and female pintails wintering in the Middle Rio Grande Valley, New Mexico, during 2001-2002 (SY1) and 2002-2003 (SY2). Sixty-nine adult male and female pintails were marked with radio-transmitters and tracked throughout the study period. Weekly relocation data in relation to study year, sex, time (week), body condition at capture, and hunting seasons were modeled using the known-fate procedure in Program MARK. Year, sex, time, and body condition covariates did not improve model performance in estimating survival, so we used the most parsimonious model to produce an overall winter survival estimate of $0.597 \pm 0.077$ (95\% C.I. $=0.442-0.735)$. Weekly survival estimates did not differ between hunting and nonhunting seasons. Male and female point estimates did not differ $\left(\chi_{1}^{2}=\right.$ $0.209, P=0.65)$. Our adult female survival estimate of $0.639 \pm 0.117(95 \%$ C.I. $=0.396-0.827)$ was $5.5 \%-28.6 \%$ lower than published estimates for adult female pintails in 5 other geographic regions. No winter survival estimates for males in other geographic regions were available for direct comparison with our study. Although relatively small sample sizes may have contributed to the lack of statistical differences in weekly survival between years, sexes, and hunting seasons, as well as to the lack of influence of body condition, relatively abundant water and food resources and absence of hunting in a refuge setting contributed to consistent survival probabilities. Because our low survival estimates, relative to other geographic regions, cannot be attributed to hunting, we postulate that natural causes of mortality play a larger role in pintail survival in our study region than in other wintering regions.
\end{abstract}

Key words: Anas acuta, New Mexico, pintail, predation, survival, Rio Grande, waterfowl, wintering ecology.

Northern Pintail (Anas acuta, hereafter "pintail") population numbers in North America have remained $>19 \%$ below their long-term average during the last 2 decades and declined to their 2nd-lowest recorded population numbers in 2002 at $58 \%$ below their long-term average (U.S. Fish and Wildlife Service 2002). This decline has continued despite increasing numbers of breeding ponds throughout prairie Canada and the north central United States and concurrent rebounding of total duck populations in the mid-1990s (Miller and Duncan 1999). Poor wintering habitat conditions may be contributing to pintail declines as reflected in declining annual survival rates and decreasing recruitment (Austin and Miller 1995). Overwinter survival rates have been estimated for pintail populations at major wintering sites in California, Louisiana, Texas, and Sinaloa, Mexico, but not in the Middle Rio Grande Valley (MRGV) of New Mexico. Improved knowledge of geographic variation in survival rates can help development of a population model for pintails to direct management actions to recover pintail numbers (Miller and Duncan 1999). Previous research on pintails and other waterfowl species has shown variation in winter survival rates among years (Moon and Haukos 2006), between sexes (Hestbeck 1993), in relation to body condition (Haramis et al. 1986, Fleskes et al. 2002, and others), and among hunting seasons (Cox et al. 1998, Fleskes et al. 2002). To contribute to the knowledge of geographic variation in pintail winter survival, we present survival estimates for pintails wintering in the MRGV in relation to year, sex, body condition on arrival, and hunting season.

\section{STUdy AREA}

The Middle Rio Grande Valley (MRGV) in New Mexico hosts 5 federal and state wildlife

\footnotetext{
${ }^{1}$ Department of Fishery and Wildlife Sciences, New Mexico State University, Las Cruces, NM 88001.

2Present address: U.S. Fish and Wildlife Service, Bosque del Apache National Wildlife Refuge, Socorro, NM 87801. E-mail: colin_lee@fws.gov

${ }^{3}$ Deceased.

${ }^{4}$ U.S. Fish and Wildlife Service, Bosque del Apache National Wildlife Refuge, Socorro, NM 87801.

5 Department of Range, Wildlife, and Fisheries Management, Texas Tech University, Lubbock, TX 79409.
} 
refuges, which cooperatively manage wetlands for waterfowl and wading avian species. Bosque del Apache National Wildlife Refuge (BDA), operated by the U.S. Fish and Wildlife Service, manages approximately 542 ha of moist-soil impoundments and maintains the largest numbers of waterfowl in the valley. Up to 10,000 pintails use the refuge throughout the winter, and peaks of $>30,000$ pass through during fall migration (USFWS unpublished data). The valley floor at BDA is perched at $1470 \mathrm{~m}$, with mountain ranges rising $2000 \mathrm{~m}$ to the west and $1600 \mathrm{~m}$ to the east. The Rio Grande Valley ranges from approximately 2 to $10 \mathrm{~km}$ in width through the study area and is surrounded by Chihuahuan desert scrub and semidesert grassland biotic communities (Brown and Lowe 1980). Additional wetlands in the MRGV, both within and outside of refuges, support more than 7000 additional wintering pintails (New Mexico Department of Game and Fish unpublished data). An important wetland in a nonrefuge setting is located approximately $37 \mathrm{~km}$ south of BDA where the Rio Grande flows into Elephant Butte Reservoir. The MRGV wetlands also serve as important stopover habitats for pintails migrating to the Mexican Interior Highlands (MIH) of Mexico (Lee 2003), where up to 473,000 pintails have been counted during January surveys (Saunders and Saunders 1981). Because the highest concentrations of pintails in the MRGV use BDA during fall migration, we captured and released all pintails at this refuge.

\section{Methods}

\section{Data Collection}

We used radiotelemetry to estimate winter survival rates during 2001-2002 and 20022003 (hereafter SY1 and SY2, respectively). Approximately 50 pintails each year were captured at BDA using baited funnel-entrance traps at feeding sites and unbaited rocket nets at loafing sites. In SY2 all ducks were captured using baited and unbaited rocket nets.

We recorded each pintail's age $(\mathrm{HY}=$ hatch year, AHY = after-hatch year) and sex (Carney $1992)$ and measured mass $( \pm 1 \mathrm{~g})$ using an electronic scale and wing chord $( \pm 1 \mathrm{~mm}$; anterior edge of wrist joint to tip of longest primary of an unflattened wing) using a ruled wing board. We estimated body condition index (BCI; Owen and Cook 1977) as

$$
\text { BCI }=\text { weight }(\mathrm{g}) / \text { wing } \operatorname{chord}(\mathrm{mm}) .
$$

This model served as an index to estimate total body fat in Mallards (Anas platyrhynchos; Ringelmann and Szymczak 1985, Haukos et al. 2001).

To minimize possible impacts of the transmitters on pintail survival, we only radiotagged individuals if the transmitter weighed $<3 \%$ of the body weight (minimum pintail weight $=766 \mathrm{~g}$ ). Each pintail included in this study received an aluminum U.S. Geological Survey band on the left leg and a 23-g radiotransmitter (Advanced Telemetry Systems, Inc., Isanti, MN), attached using a Dwyer-style backpack harness (Dwyer 1972). Transmitters were designed to exceed 180 days of transmitting time and included mortality switches that increased the pulse rate after 8 hours of inactivity. We intended to radio-tag only female pintails to produce estimates consistent and comparable with other pintail survival studies. However, we eventually marked pintails regardless of age and sex due to difficulties in capturing an adequate sample within our time frame during SY1. Only AHY males and females were included in survival analysis.

In the MRGV we located marked pintails twice per week from the ground using a truckmounted dual-Yagi antenna and receiver system. In addition, we surveyed both the MRGV and the northern MIH approximately every 2 weeks from a Cessna 205 aircraft outfitted with wingmounted dipole antennas (Gilmer et al. 1981). We detected VHF transmitters from the air reliably within a $24-\mathrm{km}$ radius at approximately $1500 \mathrm{~m}$ above ground level, and up to a $64 \mathrm{~km}$ radius under ideal conditions. From the ground, we reliably detected all transmitters within 4.5 $\mathrm{km}$, and up to $12.8 \mathrm{~km}$ at some locations. Any marked pintail that emigrated from the MRGV area was censored from the data after its last detection. Those birds returning to the MRGV were restored to the dataset upon arrival. Additional pintails were captured and released with platform transmitter terminal (PTT) satellite transmitters by researchers from the USGS Western Ecological Research Station, California (Haukos et al. 2006). PTT-marked pintails were used as an aid for locating our radio-marked pintails but were not included in this survival analysis.

Finally, we attempted to determine causes of mortality by recovering transmitters with 
mortality signals and examining the transmitters and carcasses for signs of damage typical of avian predators, mammalian predators, hunting, or transmitter loss (Miller et al. 1995). Our contact information was printed on each transmitter, and hunter-reported transmitter recoveries from within the active search area were used to determine hunting-caused deaths.

\section{Statistical Analysis}

We used Program MARK to calculate maximum-likelihood estimates of the 126-day (27 October-2 March) winter survival rate using known-fate weekly encounter history data (White and Burnham 1999). This data type allowed for entry of new individuals (left censoring) and early removal of individuals (right censoring) due to permanent emigration or transmitter failure. To avoid biasing our estimates by including pintails that were stressed due to handling or due to effects of the transmitter, we entered all pintails into analysis on the 5th day after release (Cox and Afton 1998). Initial analysis included constant versus variable survival over encounter periods ("time constant" and "time variable") as well as study year, sex, and body condition as covariates to survival probability. We considered the number of parameters, Akaike's Information Criterion (AIC), delta AIC values, AIC weights, and covariate beta values in selecting the most appropriate model; the best model would include covariates with betas considerably $>0$ and appreciably improved AIC values and weights in comparison to models with fewer parameters (Akaike 1985, Burnham and Anderson 1992). The most parsimonious model was selected to produce survival estimates for comparisons of sex, year, and hunting season. Hunting season extended through the first 12 weeks during SY1 and during weeks 7-12 during SY2. For each study year, bag limits for pintails were 1 per day.

Survival estimates by group were compared following Migoya and Baldassarre (1995) using planned contrasts and the applicable program CONTRAST (Hines and Sauer 1989, Sauer and Williams 1989). Program CONTRAST computes a $\chi^{2}$ statistic by comparing survival rates among $n$ groups. When the overall $\chi^{2}$ test was significant $(\alpha=0.05)$, planned contrasts were made. We used $t$ tests to compare average mass and BCI between males and females $(\alpha=0.05)$.

\section{Results}

Pintails immigrated into the MRGV beginning in late September and early October (Lee 2003). In SY1 we marked and released our sample of pintails between 25 October and 12 December 2001. In SY2 we completed all releases between 12 October and 27 October 2002. We marked and released 42 pintails in SY1 and 44 pintails in SY2 with radio-transmitters. We removed from analysis $9 \mathrm{HY}$ pintails (2 in SY1, 7 in SY2) and 8 pintails (4 in SY1, 4 in SY2) that permanently emigrated or died within 4 days. Thus, data from 36 AHY pintails (23 males, 13 females) in SY1 and 33 AHY pintails (15 males, 18 females) in SY2 were used in survival analysis. All means are presented with associated standard errors.

For pintails used in survival analysis (i.e., not including HY birds or AHY birds weighing < $<66 \mathrm{~g}$ ), mean body masses were $898.9 \pm$ $86.6 \mathrm{~g}$ for females $(n=31)$ and $1086.3 \pm 103.2$ $\mathrm{g}$ for males $(n=38)$. Total mean BCI values were $3.54 \pm 0.31$ for females and $4.01 \pm 0.36$ for males. Both average mass $\left(t_{1}=-7.90, P\right.$ $<<0.0001)$ and BCI $\left(t_{1}=-5.60, P<<0.0001\right)$ values differed between male and female pintails included in survival analysis.

Of the 69 radio-marked pintails included in survival analysis, 16 were known dead (9 in SY1, 7 in SY2), 43 either permanently emigrated (15 in SY1, 22 in SY2) or escaped from their transmitter harnesses (6 in SY1, 0 in SY2) and were right-censored, and 10 remained in the study area and were tracked through the entire 126-day study period (6 in SY1, 4 in SY2). Five of the radio-marked pintails that permanently emigrated were found in the Mexican Interior Highlands of Chihuahua, Mexico (Lee 2003).

All "time variable" models performed relatively poorly in our initial MARK analysis (Table 1). Additional analyses assuming "time constant" did not significantly improve with year, sex, and condition covariates. Thus, the most parsimonious model considered only constant survival over all encounter periods and sexes and yielded an overall winter survival estimate of $0.597 \pm 0.077$ (95\% C.I. $=$ 0.442-0.735).

Analysis of data by groups allowed us to calculate survival estimates specific to sex, year, and hunting season. AHY male survival (years combined) was $0.568 \pm 0.102$ (95\% C.I. 
TABLE 1. Factors and covariates used to model wintering Northern Pintail survival in the Middle Rio Grande Valley, New Mexico, during the winters of 2001-2003. Model selection criteria were number of parameters $(\mathbf{K})$, Akaike's Information Criterion $\left(\mathrm{AIC}_{c}\right), \mathrm{AIC}_{c}$ weight of model, and $\Delta \mathrm{AIC}_{c}$.

\begin{tabular}{lrccc}
\hline Model & $\mathrm{K}$ & $\mathrm{AIC}_{c}$ & Weight & $\Delta \mathrm{AIC}_{c}$ \\
\hline Time constant & 1 & 147.72 & 0.34 & 0.0 \\
Sex & 2 & 148.87 & 0.19 & 1.1 \\
Year & 2 & 149.47 & 0.14 & 1.8 \\
BCI $^{\mathrm{a}}$ & 2 & 149.57 & 0.13 & 1.9 \\
Sex + year & 3 & 150.73 & 0.08 & 3.0 \\
Sex + BCI & 3 & 150.89 & 0.07 & 3.2 \\
Year + BCI & 3 & 151.47 & 0.05 & 3.8 \\
Time & 18 & 164.32 & 0.00 & 16.6 \\
\hline
\end{tabular}

a BCI $=$ mass $(\mathrm{g}) /$ wing chord $(\mathrm{mm})$.

$=0.368-0.747)$ and AHY female survival was $0.639 \pm 0.117$ (95\% C.I. $=0.396-0.827$; Table 3). Male and female survival rates were not different $\left(\chi_{1}^{2}=0.21, P=0.65\right)$. Survival rates for each study year were $0.522 \pm 0.113(95 \%$ C.I. $=0.310-0.727)$ and $0.667 \pm 0.102(95 \%$ C.I. $=0.447-0.831)$, respectively for SY1 and SY2, and did not differ $\left(\chi_{1}^{2}=0.91, P=0.34\right)$. Finally, survival was $0.586 \pm 0.081$ (95\% C.I. $=$ $0.424-0.730)$ during hunting season and 0.612 \pm 0.079 (95\% C.I. $=0.451-0.751)$ during nonhunting season, and these estimates did not differ significantly $\left(\chi_{1}^{2}=0.05, P=0.82\right)$.

Four pintail mortalities were inaccessible on nonrefuge lands and were attributed to unknown causes of death. Causes of mortality were verified for 12 cases over both study years (Table 2). Four of these were confirmed as hunter-shot, including 1 found at a hunting blind and 3 reported directly to the principle investigator by hunters. Of the hunter mortalities, 2 were shot at state waterfowl management areas to the north of BDA, 1 was shot on the Rio Grande near Belen, NM, and 1 was shot just north of Elephant Butte Reservoir. The transmitter found at a hunting blind in a state waterfowl management area was on a bird shot illegally after pintail hunting season had closed. All other hunting mortalities were legal. The remaining 8 mortalities were categorized as natural mortalities as follows: 5 transmitters were found with extensive damage from chewing and near damaged carcasses on dry land, consistent with being preyed upon or scavenged by coyotes; 1 transmitter was found under a snag with clean-cut transmitter harness cables and with carcass damage consistent with avian predation; and 2 transmitters were not located, but emitted mortality signals from BDA where hunting was not permitted. All of the above natural mortalities occurred on BDA, so scavenged carcasses of hunter-shot birds were not an issue.

\section{Discussion}

\section{Influence of Body Condition Index and Sex on Survival}

The lack of significant contribution of BCI to subsequent winter survival is similar to the findings for AHY female pintails in southwestern Louisiana (Cox et al. 1998), the Sacramento Valley of California (Miller et al. 1995), and Sinaloa, Mexico (Migoya and Baldassarre 1995). Similarly, Miller et al. (1995) found that body mass at time of capture did not significantly contribute to winter survival. However, Fleskes et al. (2002) found body mass important in the most optimized model of pintail survival, and Moon and Haukos (2006) found body mass to have a strong positive linear relationship with survival during a drought year in the Playa Lakes Region of Texas. Several other studies also found positive relationships between survival and body condition or mass in other Anas species (Greenwood et al. 1986, Hepp et al. 1986, Reinecke and Shaiffer 1988, Conroy et al. 1989, Bergan and Smith 1993, Dufour et al.1993).

The exclusion of birds weighing less than $766 \mathrm{~g}$ may have biased our findings relating to BCI and survival because smaller-sized pintails were eliminated from consideration in favor of those in better condition or structurally larger. Alternatively, radio-tagged female birds at time of capture during this study weighed $>12 \%$ more than those in the Sinaloa study (Migoya and Baldassarre 1995), >16\% more than those reported in the Sacramento Valley study (Miller et al. 1995), and >9\% more than those in the Playa Lakes Region of Texas (Moon 2004). BCI at time of capture in this study may not have contributed to subsequent winter survival if birds either arrived in good condition or found high-quality food resources to rapidly increase mass by the time of capture and to maintain fat levels through the winter. Indeed, one may not necessarily expect heavier pintails to succeed where predation pressures are high, as in the MRGV, because an 
TABLE 2. Winter survival estimates and causes of mortality for Northern Pintails in the Middle Rio Grande Valley, New Mexico (2001-2003; this study) and at various other regions. All survival estimates are for after-hatch-year birds except for the Texas study, which includes after-hatch-year and hatch-year birds.

\begin{tabular}{|c|c|c|c|c|c|c|c|}
\hline & This study & $\mathrm{SacV}^{\mathrm{a}}$ & Sanj $^{b}$ & Louis. ${ }^{\mathrm{c}}$ & Sinaload $^{\mathrm{d}}$ & Texas $^{\mathrm{e}}$ & U.S. ${ }^{f}$ \\
\hline \multicolumn{8}{|l|}{ SURVIVAL } \\
\hline Female & $\begin{array}{c}0.639 \\
( \pm 0.117)\end{array}$ & $\begin{array}{c}0.874 \\
( \pm 0.030)\end{array}$ & $\begin{array}{c}0.756 \\
( \pm 0.034)\end{array}$ & $\begin{array}{c}0.714 \\
( \pm 0.045)\end{array}$ & $\begin{array}{c}0.911 \\
( \pm 0.020)\end{array}$ & $\begin{array}{c}0.694,0.925 \\
( \pm 0.215)\end{array}$ & 0.421 \\
\hline Male & $\begin{array}{c}0.568 \\
( \pm 0.102)\end{array}$ & $\mathrm{n} / \mathrm{a}$ & $\mathrm{n} / \mathrm{a}$ & $\mathrm{n} / \mathrm{a}$ & $\mathrm{n} / \mathrm{a}$ & $\mathrm{n} / \mathrm{a}$ & $\begin{array}{c}0.769 \\
( \pm 0.097)\end{array}$ \\
\hline \multicolumn{8}{|c|}{ MORTALITY FACTORS } \\
\hline Hunting & $4(25 \%)$ & $9(27 \%)$ & $76(83 \%)$ & $46(66 \%)$ & $11(92 \%)$ & $2,2(8 \%-25 \%)$ & $\mathrm{n} / \mathrm{a}$ \\
\hline Nonhunting & $8(50 \%)$ & $7(21 \%)$ & $16(17 \%)$ & $8(11 \%)$ & $1(8 \%)$ & $3,19(38 \%-73 \%)$ & $\mathrm{n} / \mathrm{a}$ \\
\hline Unknown & $4(25 \%)$ & $18(53 \%)$ & - & $16(23 \%)$ & - & $3,5(19 \%-38 \%)$ & $\mathrm{n} / \mathrm{a}$ \\
\hline Total & 16 & 34 & 92 & 70 & 12 & 8,26 & $\mathrm{n} / \mathrm{a}$ \\
\hline
\end{tabular}

aSacramento Valley, CA (Miller et al. 1995)

bSan Joaquin Valley, CA (Fleskes et al. 2002)

${ }^{\mathrm{c}}$ Coastal Louisiana (Cox et al. 1998)

dSinaloa, Mexico (Migova and Baldassarre 1995)

ePlaya Lakes region, Texas. The 2 estimates given are for different study years and include AHY + HY birds (Moon and Haukos 2006).

f Annual survival for pintails across the continental U.S. using band return data (Hestbeck 1993)

intermediate body mass should be maintained to maximize predator evasion (Lima 1986, McNamara and Houston 1987, Rogers 1987).

Our finding of no sex effects on winter survival, despite differences in body mass and condition index between male and female pintails, was contrary to that found by Hestbeck (1993), who estimated lower annual survival for female pintails. This result would be expected because nest mortality would be an additional factor for female pintails during the annual cycle. Also, because hunting was a small factor in pintail survival during this study (see below), survival rates were more influenced by natural mortality, which should affect sexes equally. However, female-specific estimates should continue to be the focus of pintail survival studies, because female survival is important for developing management models for this species (Flint et al. 1998) and plays a larger role in population dynamics than male survival (Cox et al 1998).

\section{Geographic and Seasonal Variation in Survival Rates}

Although winter-specific survival rates were not available for male pintails in other regions, the overall survival rate for AHY female pintails in this study was low compared to those reported for adult female pintails during winter in 5 other studies (Table 2). Specifically, our female survival estimate was $27.2 \%$ lower than that in Sinaloa, Mexico (AHY females =
$0.911 \pm 0.02$; Migoya and Baldassarre 1995), $23.5 \%$ lower than reported in Sacramento Valley, California (Miller et al. 1995); 11.7\% lower than in the San Joaquin Valley, California (Fleskes et al. 2002); $7.5 \%$ lower than in coastal Louisiana (Cox et al. 1998); and 28.6\% to $5.5 \%$ lower than in the Playa Lakes Region of Texas (Moon and Haukos 2006).

This lower survival rate in comparison to survival in other geographic regions was especially reflected in the proportion of mortalities due to natural causes. Our estimated proportion of hunter-caused mortalities was $2 \%-67 \%$ lower than those for most other published pintail winter survival studies (Table 2). On the contrary, the proportion of mortalities attributed to natural mortality was $38 \%-42 \%$ higher than those in most other published studies. The exception was during a drought year in the Playa Lakes Region of Texas when pintails were concentrated in fewer wetlands and the proportion of mortalities due to predation increased to 73\% (Moon and Haukos 2006). Similarly, Miller et al. (1995) found predation on radio-marked pintails limited to the late summer period when large numbers of pintails were concentrated in limited wetland habitat in a refuge setting.

\section{Conclusion}

Natural mortality contributed more than hunting mortality to the overall mortality rate in the MRGV/MIH compared to other regions. 
Higher densities of predators and predation rates might be expected in a refuge setting, where prey such as pintails are highly aggregated (Begon et al. 1996). Indeed, wetland sites in arid regions, such as in the MRGV, may have especially high rates of aggregation and predation in comparison to regions with more expansive wetland habitat. In such situations, providing larger and more numerous wetlands would allow pintails more options for predator avoidance.

\section{ACKNOWLEDGMENTS}

Funding was provided by the Region 2 Migratory Bird Office, USFWS; the Science Support Program, USGS; Bosque del Apache National Wildlife Refuge; T \& E, Inc.; and Friends of the Bosque del Apache. We appreciate the input to this project by G. Cooch, D. Daniel, M. Desmond, and J. Takekawa. A. Lafón-Terrazas assisted with logistics for fieldwork in Mexico. J. Savery and staff at Bosque del Apache NWR facilitated our work on the refuge throughout the study. We thank $\mathrm{M}$. Ochoa and W.S. Sherman for diligence in field data collection. R. Cox and J. Fleskes provided useful reviews. Finally, this paper is dedicated to the memory of J.P. Taylor for his endeavors and innovations in wetland management. The views in this paper are the authors' and not necessarily those of the U.S. Fish and Wildlife Service.

\section{Literature Cited}

Akaike, H. 1985. Prediction and entropy. Pages 1-24 in A.C. Atkinson and S.E. Fienberg, editors, A celebration of statistics: the ISI centenary volume. SpringerVerlag, New York.

Austin, J.E., And M.R. Miller. 1995. Northern Pintail (Anas acuta). Pages 1-32 in A. Poole and F. Gill, editors, The Birds of North America. The Academy of Natural Sciences, Philadelphia, PA.

Begon, M., J.L. Harper, and C.R. Townsend. 1996. Ecology: individuals, populations and communities. Blackwell Science, New York. 1068 pp.

Bergan, J.F., AND L.M. Smith. 1993. Survival rates of female Mallards wintering in the Playa Lakes region. Journal of Wildlife Management 57:570-577.

Brown, D.E., AND C.H. LowE. 1980. Biotic communities of the Southwest. USDA Forest Service General Technical Report RM-78, Rocky Mountain Research Station, Albuquerque, NM.

Burnham, K.P., AND D.R. Anderson. 1992. Data-based selection of an appropriate biological model: the key to modern data analysis. Pages 16-30 in D.R. McCullough and R.H. Barrett, editors, Wildlife 2001: populations. Elsevier Applied Science, New York.
Carney, S.M. 1992. Species, age, and sex identification of ducks using wing plumage. U.S. Department of the Interior, Washington, DC. $140 \mathrm{pp}$.

Conroy, M.J., G.R. Costanzo, and D.B. Stotts. 1989. Winter survival of female American Black Ducks on the Atlantic coast. Journal of Wildlife Management 53:99-109.

Cox, R.R., JR., And A.D. Afton. 1998. Effects of capture and handling on survival of female Northern Pintails. Journal of Field Ornithology 69:276-287.

Cox, R.R., JR., A.D. Afton, AND R.M. Pace, III. 1998. Survival of female Northern Pintails wintering in southwestern Louisiana. Journal of Wildlife Management 62:1512-1521.

Dufour, K.W., C.D. AnkeY, and P.J. Weatherhead. 1993. Condition and vulnerability to hunting among Mallards staging at Lake St. Clair, Ontario. Journal of Wildlife Management 57:209-215.

DwYer, T.J. 1972. An adjustable radio-package for ducks. Bird-Banding 43:282-284.

Fleskes, J.P., R.L. Jarvis, AND D.S. Gilmer. 2002. September-March survival of female Northern Pintails radiotagged in San Joaquin Valley, California. Journal of Wildlife Management 66:901-911.

Flint, P.L., J.B. GRAND, AND R.F. RockWELL. 1998. A model of Northern Pintail productivity and population growth rate. Journal of Wildlife Management 62: 1110-1118.

Gilmer, D.S., L.M. Cowardin, R.L. Duval, L.M. MechLin, C.W. Shaiffer, and V.B. Kuechle. 1981. Procedures for the use of aircraft in wildlife biotelemetry studies. U.S. Fish and Wildlife Service Resource Publication 140:1-26.

Greenwood, H., R.G. Clark, and P.J. Weatherhead. 1986. Condition bias of hunter-shot Mallards (Anas platyrhynchos). Canadian Journal of Zoology 64: 599-601.

Haramis, G.M., J.D. Nichols, K.H. Pollock, and J.E. Hines. 1986. The relationship between body mass and survival of wintering Canvasbacks. Auk 103: 506-514.

Haukos, D.A., M.R. Miller, D.L. Orthmeyer, J.Y. Takekawa, J.P. Fleskes, M.L. Casazza, W.M. Perry, and J.A. MoON. 2006. Spring migration of Northern Pintails from Texas and New Mexico, USA. Waterbirds 29:127-136.

Haukos, D.A., J.E. Neaville, and J.E. Myers. 2001. Body condition of waterfowl harvested on the Upper Gulf Coast of Texas, 1986-2000. U.S. Fish and Wildlife Service, Region 2 Migratory Bird Office, Albuquerque, NM.

Hepp G.R., R.J. Blohm, R.E. Reynolds, J.E. Hines, and J.D. Nichols. 1986. Physiological condition of autumn-banded Mallards and its relationship to hunting vulnerability. Journal of Wildlife Management 50:177-183.

Hestbeck, J.B. 1993. Survival of Northern Pintails banded during winter in North America, 1950-88. Journal of Wildlife Management 57:590-597.

Hines, J.E., AND J.R. SAUER. 1989. Program CONTRASTa general program for the analysis of several survival or recovery rate estimates. U.S. Fish and Wildlife Technical Report 24:1-7.

LEE, C.K. 2003. Distribution patterns, survival, and timeactivity budgets of Northern Pintails (Anas acuta) wintering in New Mexico and Chihuahua, Mexico. 
Master's thesis, New Mexico State University, Las Cruces.

LimA, S.L. 1986. Predation risk and unpredictable feeding conditions: determinants of body mass in birds. Ecology 67:377-385.

MCNAMARA, J.M., AND A.I. Houston. 1987. Starvation and predation as factors limiting population size. Ecology 68:1515-1519.

Migoya, R., AND G.A. BALdassarRe. 1995. Winter survival of female Northern Pintails in Sinaloa, Mexico. Journal of Wildlife Management 59:16-22.

Miller, M.R., AND D.C. Duncan. 1999. The Northern Pintail in North America: status and conservation needs of a struggling population. Wildlife Society Bulletin 27:788-800.

Miller, M.R., J.P. Fleskes, D.L. Orthmeyer, W.E. NEwTON, AND D.S. GILMER. 1995. Survival of adult female Northern Pintails in Sacramento Valley, California. Journal of Wildlife Management 59:478-486.

Moon, J. 2004. Survival, movements, and habitat use of female Northern Pintails wintering in the Playa Lakes region. Master's thesis, Texas Tech University, Lubbock.

Moon, J.A., And D.A. Haukos. 2006. Survival of female Northern Pintails wintering in the Playa Lakes region of northwestern Texas. Journal of Wildlife Management 70:777-783.

Owen, M., AND W.A. CoOK. 1977. Variations in body weight, wing length and condition of Mallard Anas platy- rhynchos platyrhynchos and their relation to environmental changes. Journal of Zoology 183:377-395.

Reinecke, K.J., AND C.W. Shaiffer. 1988. A field test for differences in condition among trapped and shot Mallards. Journal of Wildlife Management 52:227-232.

Ringelmann, J.K., AND M.P. SzymczaK. 1985. A physiological condition index for wintering Mallards. Journal of Wildlife Management 49:564-568.

Rogers, C.M. 1987. Predation risk and fasting capacity: do wintering birds maintain optimal body mass? Ecology 68:1051-1061.

SAUER, J.R., AND B.K. Williams. 1989. Generalized procedures for testing hypotheses about survival or recovery rates. Journal of Wildlife Management 53: 137-142.

Saunders, G.B., AND D.C. Saunders. 1981. Waterfowl and their wintering grounds in Mexico, 1937-64. U.S. Fish and Wildlife Service Resource Publication No. 138: $1-151$.

White, G.C., And K.P. BuRnham. 1999. Program MARK: survival estimation from populations of marked animals. Bird Study 46(supplement):S120-S138.

U.S. Fish and WildLife SERvice. 2002. Waterfowl population status, 2002. U.S. Department of the Interior, Washington, DC. 51 pp.

Received 4 April 2005 Accepted 21 August 2006 